\title{
Natural Abundance Oxygen-17 Solid-State NMR of Metal Organic Frameworks Enhanced by Dynamic Nuclear Polarization
}

Diego Carnevale, ${ }^{1 *}$ Georges Mouchaham, ${ }^{2, *}$ Sujing Wang, ${ }^{2}$ Mathieu Baudin, ${ }^{1,3}$ Christian Serre, ${ }^{2 *}$ Geoffrey Bodenhausen, ${ }^{1}$ Daniel Abergel ${ }^{1}$

\footnotetext{
${ }^{1}$ Laboratoire des biomolécules, LBM, Département de chimie, École normale supérieure, PSL University, Sorbonne Université, CNRS, 75005 Paris, France

${ }^{2}$ Institut des Matériaux Poreux de Paris, Ecole Normale Supérieure, ESPCI Paris, CNRS, PSL University, 75005 Paris, France

${ }^{3}$ Université de Paris, Laboratoire de Chimie et Biologie Pharmacologiques et Toxicologiques, CNRS UMR 8601, Université Paris Descartes, 45 rue des Saints Pères 75006 Paris France
}

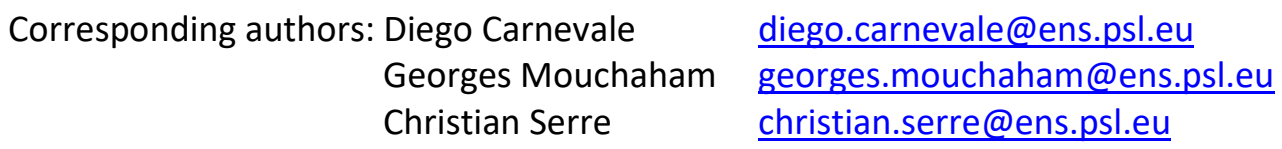




\section{Abstract}

The ${ }^{17} \mathrm{O}$ resonances of Zirconium-oxo clusters that can be found in porous $\mathrm{Zr}$ carboxylate metal-organic frameworks (MOFs) have been investigated by magic-angle spinning (MAS) NMR spectroscopy enhanced by dynamic nuclear polarization (DNP). High-resolution ${ }^{17} \mathrm{O}$ spectra at $0.037 \%$ natural abundance could be obtained in 48 hours, thanks to DNP enhancement of the ${ }^{1} \mathrm{H}$ polarization by factors $\varepsilon\left({ }^{1} \mathrm{H}\right)=\mathrm{S}_{\text {with }} / \mathrm{S}_{\text {without }}=28$, followed by ${ }^{1} \mathrm{H} \rightarrow{ }^{17} \mathrm{O}$ cross-polarization, allowing a saving in experimental time by a factor of $c a$. 800 . The distinct ${ }^{17} \mathrm{O}$ sites from the oxoclusters can be resolved at $18.8 \mathrm{~T}$. Their assignment is supported by density functional theory (DFT) calculations of chemical shifts and quadrupolar parameters. Protonation of ${ }^{17} \mathrm{O}$ sites seems to be leading to large characteristic shifts. Markedly, natural abundance ${ }^{17} \mathrm{O} N M R$ spectra of diamagnetic MOFs can thus be used to probe and characterize the local environment of different ${ }^{17} \mathrm{O}$ sites on an atomic scale.

\section{Table of Content Graphic}
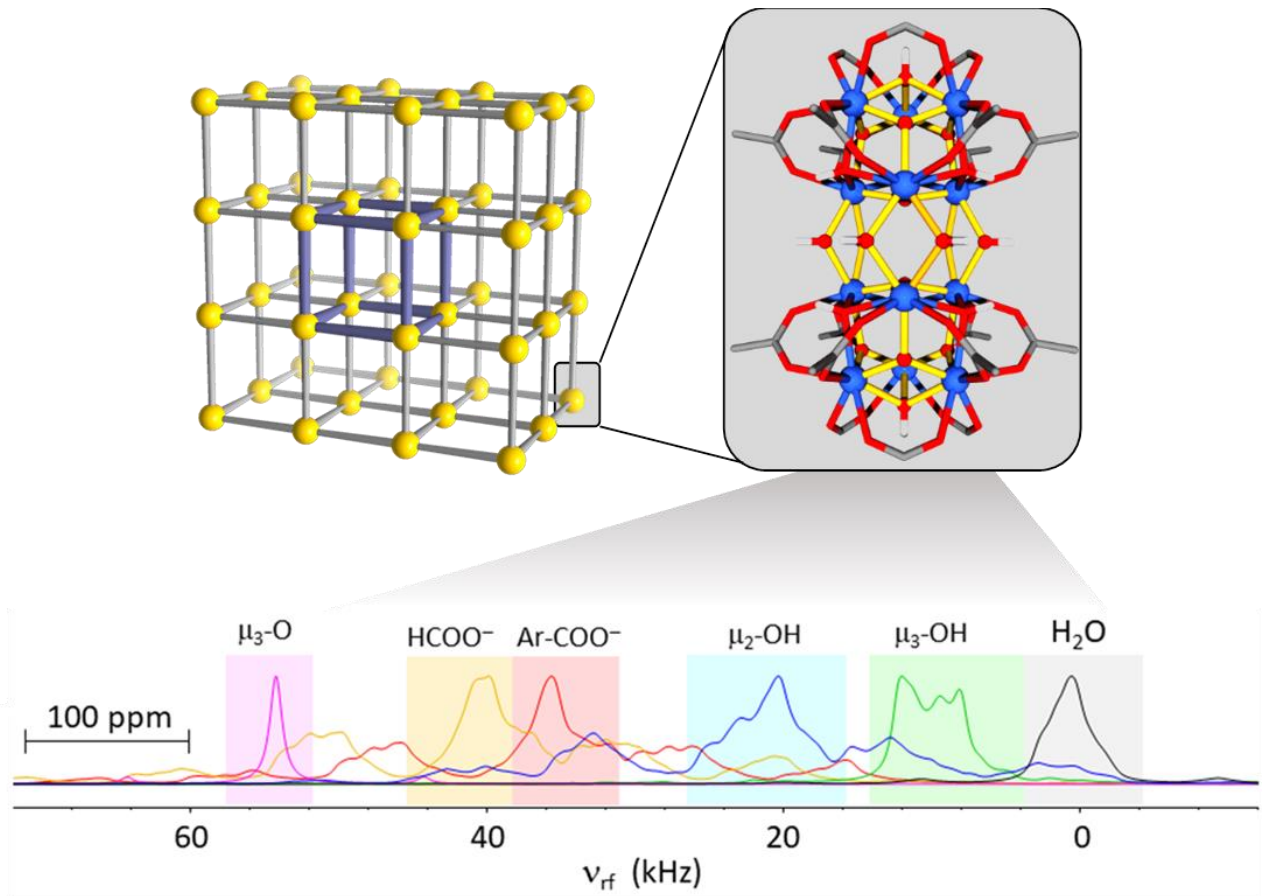

\section{Key words}

Oxygen-17 NMR, Solid-State NMR, Magic Angle Spinning, Dynamic Nuclear Polarization, Metal-Organic Frameworks, Zirconium-Oxo Clusters. 


\section{Introduction}

Metal-Organic Frameworks (MOFs) are a class of hybrid porous materials that have attracted considerable attention in the last few decades. Their highly porous structures, that can be easily modulated in terms of their chemical nature and pore dimensions, have made them promising candidates for various potential applications in different fields related to environment, energy and health. ${ }^{[1,2]}$

For any realistic application, one of the main expected features of MOFs is their ability to be manipulated under ambient conditions (such as in the presence of moisture), or even more stringent ones (such as in physiological or corrosive media) in the case of more advanced applications. This aptitude (or chemical stability) is directly related to the strength of the coordination bonds connecting the organic and inorganic moieties. However, obtaining highly robust MOFs requires, in general, the use of high valence cations (e.g., $\mathrm{Fe}^{3+}, \mathrm{Al}^{3+}, \mathrm{Zr}^{4+}, \mathrm{Ti}^{4+}, \ldots$ ) and/or organic functional groups to form strong interactions, ${ }^{[3,4]}$ which makes it challenging. This subsequently affects the crystallization process, often leading to amorphous products or, at best, to nanocrystalline powders. ${ }^{[5,6]}$ Thus, this renders structural elucidation of the crystalline framework very challenging, and in some cases characterization techniques such as X-ray or even electron diffraction reach their limits, particularly when unit cells are large and/or structural complexity is involved.

In this regard, the use of advanced complementary techniques becomes more and more useful to assist structure elucidation. Solid-state NMR is one of the ideal complementary techniques to diffraction as it is sensitive to nuclear sites on an atomic scale while it does not require large crystals or the presence of long-range order. The anisotropic interactions that determine the NMR line shapes in the solid state (e.g., chemical or paramagnetic shifts, dipolar or quadrupolar couplings) and that provide precious structural information can be probed with specifically designed experiments. ${ }^{[7]}$ The NMR parameters thus obtained can then be compared with those calculated by means of DFT methods ${ }^{[8,9]}$ and serve to validate different structural hypotheses and assist structural refinement. ${ }^{[10-16]}$ The combination of MAS NMR spectroscopy 
and DFT calculations has become known as "NMR crystallography" and has found successful applications in a multitude of studies. ${ }^{[17]}$

For the structural elucidation of a MOF, an accurate description of the constitutive inorganic building units (IBUs) and their sites is a crucial step. Indeed, acquiring a clear insight into both the nuclearity (i.e., discrete or extended) and the coordination (i.e., oxo/hydroxo groups, edge or corner shared MOx, connectivity, etc.) of an IBU represents a key steppingstone in structure resolution. In addition to the metal cations, the oxygen atoms are of particular importance when dealing with MOF's IBUs. ${ }^{[18]}$ The ${ }^{17} \mathrm{O}$ sites comprise very useful information with regard to the composition of an IBU and the site of the metal cations since inorganic ligands, such as oxo- and hydroxo-bridges (which can have various coordination geometries) and organic ligands (coordinating functions such as carboxylates, phenolates, phosphates, etc.) all represent distinct ${ }^{17} \mathrm{O}$ environments.

However, Oxygen-17 NMR spectroscopy is limited by a low natural abundance $(0.037 \%)$, an unfavorable Larmor frequency $\left(\gamma\left({ }^{17} \mathrm{O}\right) / \gamma\left({ }^{1} \mathrm{H}\right)=0.14\right)$, and a large quadrupolar interaction, with quadrupolar splitting $\omega_{Q}$ that can reach several $\mathrm{MHz}$ (spin $S=5 / 2$ ). All ${ }^{17} \mathrm{O}$ spectra arise from the central transition (CT) between the states $m=+1 / 2$ and $m=-1 / 2$, which is only broadened by the second-order quadrupolar interaction by a few $\mathrm{kHz}$. In contrast, the satellite transitions between the states $m= \pm 5 / 2$ and $m= \pm 3 / 2$, as well as those between the states $m= \pm 3 / 2$ and $m= \pm 1 / 2$, are usually not observable because they are broadened to first-order and span several $\mathrm{MHz}$. All of these factors greatly limit sensitivity and spectral resolution, even in samples spinning at the magic angle (MAS). ${ }^{[19]}$ Several NMR studies of isotopically enriched ${ }^{17} \mathrm{O} N M R$ of $\mathrm{MOFs}^{[20]}$ or other materials ${ }^{[21-23]}$ have been reported so far. However, isotopic enrichment is often challenging from the synthesis point of view, and invariably expensive. In addition, there is no guarantee that all oxygen sites from the structure are uniformly enriched during the synthesis or the post-synthetic treatment, which makes any tentative quantification highly dubious. To the best of our knowledge, only a single study of silica gel surfaces has made use of dynamic nuclear polarization (DNP) enhanced MAS of ${ }^{17} \mathrm{O}$ in natural abundance. ${ }^{[24]}$ Extending 
the use of this powerful tool to MOFs represents a significant leap forward in their structural elucidation and atomic scale characterization.

Over the past decade, DNP has emerged as an invaluable tool to boost the intensity of NMR signals. ${ }^{[25-28]}$ By saturating the EPR transitions of suitable radical species, used to dope the samples, by means of microwave irradiation, it is possible to greatly enhance the polarization or population difference between the nuclear spin energy levels, and hence to increase nuclear signal intensities by a factor $\varepsilon=\mathrm{S}_{\text {with }} / \mathrm{S}_{\text {without, }}$ where $\varepsilon$ is the ratio of signal intensities recorded on the same sample with and without microwave irradiation, by one or two orders of magnitude. This has allowed investigations of dilute chemical species or low-abundant nuclei that would have been otherwise prohibitive in terms of experimental times. ${ }^{[29-32]}$

In the following, we present unprecedented natural abundance ${ }^{17} \mathrm{O}$ spectra obtained through DNP-enhanced MAS NMR experiments of a porous Zr-oxo-cluster carboxylate-based MOF. The ${ }^{1} \mathrm{H}$ nuclei are hyperpolarized by DNP prior to cross-polarization from ${ }^{1} \mathrm{H}$ to ${ }^{17} \mathrm{O}$ to obtain the sensitivity required to detect different ${ }^{17} \mathrm{O}$ sites in the material. Moreover, the use of DFT methods to calculate the chemical shielding anisotropy (CSA) and electric-field gradient (EFG) tensors allowed us to identify and assign all ${ }^{17} \mathrm{O}$ sites in the material, thereby providing valuable structural information. Our observations prove that the ${ }^{17} \mathrm{O}$ sites are very sensitive to local structure and feature characteristic lineshapes for different sites.

\section{Results and discussion}

In this study, we sought to investigate a porous $\mathrm{Zr}$ polycarboxylate based MOF for several reasons. Indeed, in addition to being diamagnetic, this family of materials, widely studied in the last decade, offers a large diversity in terms of chemistry (IBU, nuclearity and connectivity), topology and pore dimensions. ${ }^{[3]}$ To perform our study, we have selected an in-house MOF, namely, MIP-206 (where MIP stands for Materials of the Institute of porous materials from Paris), which is chemically robust and conserves its integrity under the experimental conditions in which the DNP-MAS NMR measurements are performed (presence of water). It is also endowed by large channels of ca. $2.6 \mathrm{~nm}$ in diameter, thereby ensuring accessibility to the 
solution ("DNP juice") containing radicals. Moreover, this MOF is built with two different IBUs, Zr12-oxo-clusters (I) and Zr6-oxo-clusters (II), together with benzoate ligands. The detailed crystalline structure of MIP-206 will be reported elsewhere. The dodecanuclear oxo-cluster (I) is depicted in Figure 1. It is coordinated to 12 benzoate groups (L-COO) and 6 formate groups, and can be formulated as $\left[\mathrm{Zr}_{12}\left(\mu_{3}-\mathrm{O}\right)_{8}\left(\mu_{3}-\mathrm{OH}\right)_{8}\left(\mu_{2}-\mathrm{OH}\right)_{6}(\mathrm{HCOO})_{6}(\mathrm{~L}-\mathrm{COO})_{12}\right]$ or as $\left[\mathrm{Zr}_{6}\left(\mu_{3-}-\mathrm{O}_{4}\left(\mu_{3^{-}}\right.\right.\right.$ $\left.\mathrm{OH})_{4}\left(\mu_{2}-\mathrm{OH}\right)_{3}(\mathrm{HCOO})_{3}(\mathrm{~L}-\mathrm{COO})_{6}\right]_{2}$. Interestingly, (I) shows, in particular, $\mu_{2}$-oxo/hydroxo bridges that are a very distinctive of Zr12-oxo-clusters (I), ${ }^{[34]}$ in contrast to the $\mu_{3}$-oxo/hydroxo bridges that can be also found in the more common Zr6-oxo-clusters (II).

As all different ${ }^{17} \mathrm{O}$ sites in the full unit cell are also found in these substructures, only these oxo-clusters were utilized to perform DFT calculations of the NMR parameters so as to keep the computational time within reasonable bounds. Carboxylate functional groups of the aromatic cores that are involved in binding to the zirconium centers of the neighboring $\mathrm{Zr}$-oxocluster were substituted by methyl groups to further reduce computational costs. The nearest remaining carboxylic ${ }^{17} \mathrm{O}$ sites are 5 bonds away from the truncation site. This strategy ensures minimal perturbation of the electronic environment of the ${ }^{17} \mathrm{O}$ sites in the $\mathrm{Zr}$-oxo-clusters while allowing the computation of meaningful NMR parameters.

A ${ }^{1} \mathrm{H}$ spectrum of a sample of ca. $30 \mathrm{mg}$ of MIP-206 impregnated with a $13 \mathrm{mM}$ solution of $A M U P o{ }^{[35]}$ in $\mathrm{D}_{2} \mathrm{O} / \mathrm{H}_{2} \mathrm{O}(\mathrm{vol} / \mathrm{vol}=90 / 10)$, spinning at the magic angle at $10 \mathrm{kHz}$ in a sapphire rotor of $3.2 \mathrm{~mm}$ diameter in a static field of $B_{0}=18.8 \mathrm{~T}\left(800 \mathrm{MHz}\right.$ for protons, $108.5 \mathrm{MHz}$ for $\left.{ }^{17} \mathrm{O}\right)$ is given in Fig. S1 of the Supporting Information, where proton spectra acquired with and without microwave irradiation show an enhancement $\varepsilon\left({ }^{1} \mathrm{H}\right)=28$.

This enhanced polarization has been exploited to acquire ${ }^{17} \mathrm{O}$ spectra at natural abundance by means of cross polarization (CP). The results are shown in Fig. 2(a). It is important to remark that $\mathrm{CP}$ spectra are often not quantitative, i.e., the signal areas are generally not proportional to the number of oxygen atoms in each site, as the efficiency of polarization transfer from the surrounding proton bath to ${ }^{17} \mathrm{O}$ may be site specific. The most intense ${ }^{17} \mathrm{O}$ peak is due to water molecules $\left(\mathrm{H}_{2} \mathrm{O}, \mathrm{HDO}\right.$ and $\left.\mathrm{D}_{2} \mathrm{O}\right)$ in the frozen polarizing solution (the "DNP juice"). An expansion of this spectrum is shown in Fig. 2(b), where one can identify different ${ }^{17} \mathrm{O}$ 
sites at higher frequencies. The only spinning sideband that does not overlap with centerbands of other sites is highlighted by an asterisk in (b) and is due to water molecules in the DNP juice. Fig. 2(c-j) show simulations of ${ }^{17} \mathrm{O}$ peaks based on the NMR parameters obtained by means of DFT methods on the cluster of Fig. 1. The blue spectrum of 3(c) results from the sum of all relevant (red) ${ }^{17} \mathrm{O}$ spectra. The agreement between the experiment and simulations is remarkably good. The simulated ${ }^{17} \mathrm{O}$ spectrum of Fig. 2(d) corresponds to the water molecules in the DNP juice and was simulated assuming quadrupolar parameters for ice reported in the literature. ${ }^{[36,37]}$ The shift parameters were calculated ex-novo in this study for a cluster of 6 water molecules (See Supporting Information). The simulated linewidth, which is mostly due to second-order quadrupole interactions, reproduces very well the linewidth observed experimentally. The spectra shown in $3(d-j)$ are due to various ${ }^{17} \mathrm{O}$ sites of the MOF that are generally well resolved at this field. Overall, one can appreciate a clear correspondence between the experimentally observed line shapes and those calculated for our Zr12-oxo-cluster (I), thus proving the pertinence of our simplified model of Fig. 1(b). The shift and quadrupolar parameters utilized in these simulations are given in Table S1. It is interesting to note that the carboxylic and $\mu_{2}-\mathrm{OH}$ sites are characterized by a relatively large CSA, resulting in extensive spinning sideband patterns that make it challenging to identify the central transition. These sideband patterns are due to second-order cross terms between quadrupolar and shift interactions that cannot be averaged out by magic-angle spinning. ${ }^{[38,39]}$ For the $\mu_{3}-\mathrm{OH}$ sites, on the other hand, the central transitions can be clearly identified in the simulated spectra. An unprotonated $\mu_{3}-\mathrm{O}$ site is predicted to have an almost negligible quadrupolar broadening, resulting in nearly isotropic lines (orange spectrum in Fig. 2). Since we found no experimental evidence for any sharp peaks in the relevant spectral region, we postulated that these sites must be protonated. This hypothesis was investigated in silico and the simulated spectrum for a protonated $\mu_{3}-\mathrm{OH}$ site is shown in (j). These results indeed confirm that this site is protonated upon impregnation of the MOF with the DNP juice. We are planning further investigations with water-free DNP juice to ascertain this hypothesis.

In order to test how quadrupolar and shift NMR parameters can be used to distinguish between different ${ }^{17} \mathrm{O}$ sites in MOF materials, an analogous DFT study was conducted on a Zr6- 
oxo-cluster (II) whose structure and composition are very similar to half of the Zr12-oxo-cluster (I) but without the bridging $\mu_{2}-\mathrm{O}$ sites. The corresponding structure is shown in Figure $3(\mathrm{a}, \mathrm{b})$. For the sake of comparison, a series of simulated spectra for the various ${ }^{17} \mathrm{O}$ sites of the $\mathrm{Zr} 12$ oxo-cluster (I) of Fig. 1 is shown in Fig. 3(c). The simulated spectra for Zr6-oxo-cluster (II) are shown in Fig. 3 (d). Different sites are highlighted by coloured boxes. One can easily identify in the spectrum of $(\mathrm{d})$ the absence of $\mu_{2}-\mathrm{O}$ sites (emphasized by a vertical blue arrow). Markedly, this represents a clear distinctive feature that can provide valuable information for the structural elucidation step. The peak associated with water in the DNP juice is shown in (e) to guide the eye. The first set of spinning sidebands, corresponding to ${ }^{17} \mathrm{O}$ sites with large CSAs, are indicated by asterisks with the same colour coding. Undoubtably, these results prove the power of NMR spectroscopy, in combination with DNP enhancement and DFT methods, in discerning and characterizing different ${ }^{17} \mathrm{O}$ sites in MOFs on the atomic scale, which can be particularly helpful for structural elucidation. In addition, our simulations also point to possible limitations of this kind of studies: extensive spinning sideband patterns arising from ${ }^{17} \mathrm{O}$ species with large CSAs (mainly carboxylic functions and bridging $\mu_{2}-\mathrm{O}$ sites) are expected to overlap at the slow spinning rates commonly utilized in DNP experiments. The implementation of MQMAS ${ }^{[40]}$ or STMAS ${ }^{[41]}$ techniques in combination with $\mathrm{CP}^{[30]}$ from hyperpolarized protons to ${ }^{17} \mathrm{O}$ offers a possible strategy to circumvent these hurdles.

\section{Conclusions}

The ${ }^{17} \mathrm{O}$ resonances in a (meso)porous $\mathrm{Zr}$-oxo-cluster based MOF have been investigated for the first time by means of DNP-enhanced MAS NMR at natural $0.037 \%$ isotopic abundance. An AMUPol solution was used as the impregnating agent. Upon microwave irradiation, an enhancement of ca. 28 of the ${ }^{1} \mathrm{H}$ polarization was obtained. The hyperpolarized ${ }^{1} \mathrm{H}$ magnetization was transferred to ${ }^{17} \mathrm{O}$ by means of ${ }^{1} \mathrm{H} \rightarrow{ }^{17} \mathrm{O}$ cross-polarization. This allowed us to record one-dimensional ${ }^{17} \mathrm{O}$ spectra without isotopic enrichment in ca. 48 hours. Anisotropic shielding and electric-field gradient tensors were calculated by means of DFT methods. This enabled us to assign the experimental ${ }^{17} \mathrm{O}$ peaks, where a remarkable agreement between the experimental and simulated spectra has been obtained. The carboxylic and bridging $\mu_{2}-\mathrm{O}$ sites 
feature large chemical shift anisotropies. The ${ }^{17} \mathrm{O}$ sites has proven to be very sensitive to local structure and can be utilized for the structural characterization of MOF materials. In summary, signal enhancement by DNP opens new avenues to perform ${ }^{17} \mathrm{O}$ NMR of diamagnetic MOF samples in natural abundance and, as demonstrated in this study, can be of particular interest in assisting the structural elucidation of novel MOFs and/or to study in the future the "ligand defect" phenomenon ${ }^{[42]}$ that MOFs may suffer (or benefit) from. DFT calculations show that all ${ }^{17} \mathrm{O}$ sites, including bridging $\mu_{2}-\mathrm{O}$ sites, appear in well-defined spectral regions that do not overlap at $18.8 \mathrm{~T}$.

\section{Experimental details}

NMR. The dry material was impregnated with a solution ("DNP juice") of $13 \mathrm{mM} \mathrm{AMUPOL}$ in $\mathrm{D}_{2} \mathrm{O}: \mathrm{H}_{2} \mathrm{O}=90: 10$ (v:v) without any cryoprotectant and transferred to a $3.2 \mathrm{~mm}$ sapphire rotor. The CP spectra were recorded at $T=100 \mathrm{~K}$ in a $B_{0}=18.8 \mathrm{~T}$ magnet $\left(800.1\right.$ and $108.5 \mathrm{MHZ}$ for ${ }^{1} \mathrm{H}$ and ${ }^{17} \mathrm{O}$, respectively) coupled with a $527 \mathrm{GHz}$ gyrotron and utilizing a spinning rate $v_{\mathrm{R}}=10 \mathrm{kHz}$. The rf-field strength for the $90^{\circ}{ }^{1} \mathrm{H}$ pulse was $100 \mathrm{kHz}$ and the contact time for the crosspolarization step was $\tau_{c}=3 \mathrm{~ms}$, with rf field strengths of 65 and $26 \mathrm{kHz}$ for ${ }^{1} \mathrm{H}$ and ${ }^{17} \mathrm{O}$, respectively. The spectra were referenced to adamantane and $\mathrm{H}_{2} \mathrm{O}$, for ${ }^{1} \mathrm{H}$ and ${ }^{17} \mathrm{O}$, respectively. Numerical simulations were performed with SIMPSON $^{[43]}$ and employed $8 \times 320$ crystal orientations sampled with the REPULSION scheme. ${ }^{[44]}$

DFT calculations. DFT calculations were performed utilizing Gaussian09. ${ }^{[45]}$ The structure of the Zr12 cluster (I) shown in Fig. 1 was optimized with the B3LYP functional ${ }^{[46,47]}$ utilizing the Pople basis sets ${ }^{[48]} 3-21 G$ (for ${ }^{1} \mathrm{H}$ and ${ }^{13} \mathrm{C}$ ), 6-311+G(d) (for ${ }^{17} \mathrm{O}$ ) and the LANL2DZ pseudopotential (for $\mathrm{Zr}$ ). ${ }^{[49-51]}$ The optimized geometry was subsequently utilized for the calculation of magnetic shielding and EFG tensors with the GIAO method ${ }^{[52,53]}$ at the same level of theory. Subsequently, a single ${ }^{1} \mathrm{H}$ nucleus was positioned in the proximity of a $\mu 3-0$ moiety. Geometry optimization allowed the position of this proton to be optimized, while the remaining structure was kept frozen. The resulting geometry was utilized for the calculations of NMR parameters as described above. Only the relevant $\mu 3-0$ site was considered in this latter case. 
Natural abundance oxygen-17 solid-state NMR of metal organic frameworks enhanced by dynamic nuclear polarization

The EFGShield software ${ }^{[54]}$ was utilized to extract the calculated NMR parameters. Cartesian coordinates are given in Supplementary Information.

\section{Acknowledgements}

This work was performed using HPC resources from GENCI-TGCC (Grant 2019AP010910927), the Equipex grant "Paris en resonance" (ANR-10-EQPX-09) and the ERC grant "Dilute para-water" (grant agreement 339754). SW and CS are grateful to the ANR Project MeaCoPA (ANR-17-CE29-0003) for financial support. All authors acknowledge support by the Paris Ile-de-France Region / Respore program. 
Natural abundance oxygen-17 solid-state NMR of metal organic frameworks enhanced by dynamic nuclear polarization

\section{References}

[1] H.-C. Zhou, J. R. Long, O. M. Yaghi, Chem. Rev. 2012, 112, 673-674.

[2] G. Maurin, C. Serre, A. Cooper, G. Férey, Chem. Soc. Rev. 2017, 46, 3104-3107.

[3] T. Devic, C. Serre, Chem. Soc. Rev. 2014, 43, 6097-6115.

[4] H. Assi, G. Mouchaham, N. Steunou, T. Devic, C. Serre, Chem. Soc. Rev. 2017, 46, 3431-3452.

[5] G. Mouchaham, S. Wang, C. Serre, in Met. Fram., Wiley-VCH Verlag GmbH \& Co. KGaA, Weinheim, Germany, 2018, pp. 1-28.

[6] S. Yuan, L. Feng, K. Wang, J. Pang, M. Bosch, C. Lollar, Y. Sun, J. Qin, X. Yang, P. Zhang, Q. Wang, L. Zou, Y. Zhang, L. Zhang, Y. Fang, J. Li, H.-C. Zhou, Adv. Mater. 2018, 30, 1704303.

[7] M. J. Duer, Ed. , Solid-State NMR Spectroscopy Principles and Applications, Blackwell Science Ltd, Oxford, UK, 2001.

[8] C. Bonhomme, C. Gervais, F. Babonneau, C. Coelho, F. Pourpoint, T. Azaïs, S. E. Ashbrook, J. M. Griffin, J. R. Yates, F. Mauri, C. J. Pickard, Chem. Rev. 2012, 112, 5733-5779.

[9] S. E. Ashbrook, D. McKay, Chem. Commun. 2016, 52, 7186-7204.

[10] D. Carnevale, V. del Amo, D. Philp, S. E. Ashbrook, Tetrahedron 2010, 66, 6238-6250.

[11] M. Castro, V. R. Seymour, D. Carnevale, J. M. Griffin, S. E. Ashbrook, P. A. Wright, D. C. Apperley, J. E. Parker, S. P. Thompson, A. Fecant, N. Bats, J. Phys. Chem. C 2010, 114, 12698-12710.

[12] M. R. Mitchell, D. Carnevale, R. Orr, K. R. Whittle, S. E. Ashbrook, J. Phys. Chem. C 2012, 116, 4273-4286.

[13] D. Carnevale, S. E. Ashbrook, G. Bodenhausen, RSC Adv. 2014, 4, 56248-56258.

[14] E. Banach, C. Invernizzi, M. Baudin, R. Neier, D. Carnevale, Phys. Chem. Chem. Phys. 2017, 19, 55255539.

[15] D. Carnevale, B. Grosjean, G. Bodenhausen, Commun. Chem. 2018, 1, 1-9.

[16] D. Carnevale, M. Hollenstein, G. Bodenhausen, ChemPhysChem 2020, DOI 10.1002/cphc.201901214.

[17] R. K. (Robin K. Harris, R. E. Wasylishen, M. J. Duer, NMR Crystallography, Wiley, 2009.

[18] M. J. Kalmutzki, N. Hanikel, O. M. Yaghi, Sci. Adv. 2018, 4, eaat9180.

[19] S. E. Ashbrook, M. E. Smith, Chem. Soc. Rev. 2006, 35, 718-735.

[20] P. He, J. Xu, V. V. Terskikh, A. Sutrisno, H.-Y. Nie, Y. Huang, J. Phys. Chem. C 2013, 117, 16953-16960.

[21] G. P. M. Bignami, Z. H. Davis, D. M. Dawson, S. A. Morris, S. E. Russell, D. McKay, R. E. Parke, D. Iuga, R. E. Morris, S. E. Ashbrook, Chem. Sci. 2018, 9, 850-859.

[22] A. Fernandes, R. F. Moran, S. Sneddon, D. M. Dawson, D. McKay, G. P. M. Bignami, F. Blanc, K. R. Whittle, S. E. Ashbrook, RSC Adv. 2018, 8, 7089-7101.

[23] S. L. Carnahan, B. J. Lampkin, P. Naik, M. P. Hanrahan, I. I. Slowing, B. VanVeller, G. Wu, A. J. Rossini, J. Am. Chem. Soc. 2019, 141, 441-450. 
[24] F. A. Perras, T. Kobayashi, M. Pruski, J. Am. Chem. Soc. 2015, 137, 8336-8339.

[25] T. Maly, G. T. Debelouchina, V. S. Bajaj, K.-N. Hu, C.-G. Joo, M. L. Mak-Jurkauskas, J. R. Sirigiri, P. C. A. van der Wel, J. Herzfeld, R. J. Temkin, R. G. Griffin, J. Chem. Phys. 2008, 128, 052211.

[26] A. B. Barnes, G. De Paëpe, P. C. A. van der Wel, K.-N. Hu, C.-G. Joo, V. S. Bajaj, M. L. Mak-Jurkauskas, J. R. Sirigiri, J. Herzfeld, R. J. Temkin, R. G. Griffin, Appl. Magn. Reson. 2008, 34, 237-263.

[27] A. Lesage, M. Lelli, D. Gajan, M. A. Caporini, V. Vitzthum, P. Miéville, J. Alauzun, A. Roussey, C. Thieuleux, A. Mehdi, G. Bodenhausen, C. Coperet, L. Emsley, J. Am. Chem. Soc. 2010, 132, 15459-15461.

[28] A. S. Lilly Thankamony, J. J. Wittmann, M. Kaushik, B. Corzilius, Prog. Nucl. Magn. Reson. Spectrosc. 2017, 102-103, 120-195.

[29] M. Lelli, D. Gajan, A. Lesage, M. A. Caporini, V. Vitzthum, P. Miéville, F. Héroguel, F. Rascón, A. Roussey, C. Thieuleux, M. Boualleg, L. Veyre, G. Bodenhausen, C. Coperet, L. Emsley, J. Am. Chem. Soc. 2011, 133, 2104-2107.

[30] V. Vitzthum, P. Miéville, D. Carnevale, M. A. Caporini, D. Gajan, C. Copéret, M. Lelli, A. Zagdoun, A. J. Rossini, A. Lesage, L. Emsley, G. Bodenhausen, Chem. Commun. 2012, 48, 1988-1990.

[31] I. Gelis, V. Vitzthum, N. Dhimole, M. A. Caporini, A. Schedlbauer, D. Carnevale, S. R. Connell, P. Fucini, G. Bodenhausen, J. Biomol. NMR 2013, 56, 85-93.

[32] F. Pourpoint, A. S. L. Thankamony, C. Volkringer, T. Loiseau, J. Trébosc, F. Aussenac, D. Carnevale, G. Bodenhausen, H. Vezin, O. Lafon, J.-P. Amoureux, Chem. Commun. 2014, 50, 933-935.

[33] Y. Bai, Y. Dou, L.-H. Xie, W. Rutledge, J.-R. Li, H.-C. Zhou, Chem. Soc. Rev. 2016, 45, 2327-2367.

[34] M. J. Cliffe, E. Castillo-Martínez, Y. Wu, J. Lee, A. C. Forse, F. C. N. Firth, P. Z. Moghadam, D. FairenJimenez, M. W. Gaultois, J. A. Hill, O. V. Magdysyuk, B. Slater, A. L. Goodwin, C. P. Grey, J. Am. Chem. Soc. 2017, 139, 5397-5404.

[35] C. Sauvée, M. Rosay, G. Casano, F. Aussenac, R. T. Weber, O. Ouari, P. Tordo, Angew. Chemie Int. Ed. 2013, 52, 10858-10861.

[36] E. G. Keeler, V. K. Michaelis, R. G. Griffin, J. Phys. Chem. B 2016, 120, 7851-7858.

[37] E. G. Keeler, V. K. Michaelis, C. B. Wilson, I. Hung, X. Wang, Z. Gan, R. G. Griffin, J. Phys. Chem. B 2019, 123, 3061-3067.

[38] S. E. Ashbrook, J. McManus, M. J. Thrippleton, S. Wimperis, Prog. Nucl. Magn. Reson. Spectrosc. 2009, 55, 160-181.

[39] D. Carnevale, P. Pelupessy, G. Bodenhausen, J. Phys. Chem. Lett. 2019, 10, 3224-3231.

[40] A. Medek, J. S. Harwood, L. Frydman, J. Am. Chem. Soc. 1995, 117, 12779-12787.

[41] Z. Gan, J. Am. Chem. Soc. 2000, 122, 3242-3243.

[42] L. Liu, Z. Chen, J. Wang, D. Zhang, Y. Zhu, S. Ling, K.-W. Huang, Y. Belmabkhout, K. Adil, Y. Zhang, B. Slater, M. Eddaoudi, Y. Han, Nat. Chem. 2019, 11, 622-628.

[43] M. Bak, J. T. Rasmussen, N. C. Nielsen, J. Magn. Reson. 2000, 147, 296-330.

[44] M. Bak, N. C. Nielsen, J. Magn. Reson. 1997, 125, 132-139.

[45] M. J. Frisch, G. W. Trucks, H. B. Schlegel, G. E. Scuseria, M. A. Robb, J. R. Cheeseman, G. Scalmani, V. 
Barone, B. Mennucci, G. A. Petersson, H. Nakatsuji, M. Caricato, X. Li, H. P. Hratchian, A. F. Izmaylov, J. Bloino, G. Zheng, J. L. Sonnenberg, M. Hada, M. Ehara, K. Toyota, R. Fukuda, J. Hasegawa, M. Ishida, T. Nakajima, Y. Honda, O. Kitao, H. Nakai, T. Vreven, J. Montgomery, J. A., J. E. Peralta, F. Ogliaro, M. Bearpark, J. J. Heyd, E. Brothers, K. N. Kudin, V. N. Staroverov, R. Kobayashi, J. Normand, K. Raghavachari, A. Rendell, J. C. Burant, S. S. Iyengar, J. Tomasi, M. Cossi, N. Rega, J. M. Millam, M. Klene, J. E. Knox, J. B. Cross, V. Bakken, C. Adamo, J. Jaramillo, R. Gomperts, R. E. Stratmann, O. Yazyev, A. J. Austin, R. Cammi, C. Pomelli, J. W. Ochterski, R. L. Martin, K. Morokuma, V. G. Zakrzewski, G. A. Voth, P. Salvador, J. J. Dannenberg, S. Dapprich, A. D. Daniels, Ö. Farkas, J. B. Foresman, J. V. Ortiz, J. Cioslowski and D. J. Fox, Gaussian, Inc., Wallingford CT, 2009.

[46] A. D. Becke, J. Chem. Phys. 1993, 98, 5648-5652.

[47] C. Lee, W. Yang, R. G. Parr, Phys. Rev. B 1988, 37, 785-789.

[48] R. Ditchfield, W. J. Hehre, J. A. Pople, J. Chem. Phys. 1971, 54, 724-728.

[49] P. J. Hay, W. R. Wadt, J. Chem. Phys. 1985, 82, 299-310.

[50] W. R. Wadt, P. J. Hay, J. Chem. Phys. 1985, 82, 284-298.

[51] P. J. Hay, W. R. Wadt, J. Chem. Phys. 1985, 82, 270-283.

[52] D. Zeroka, H. F. Hameka, J. Chem. Phys. 1966, 45, 300-311.

[53] R. Ditchfield, J. Chem. Phys. 1972, 56, 5688-5691.

[54] S. Adiga, D. Aebi, D. L. Bryce, Can. J. Chem. 2007, 85, 496-505. 

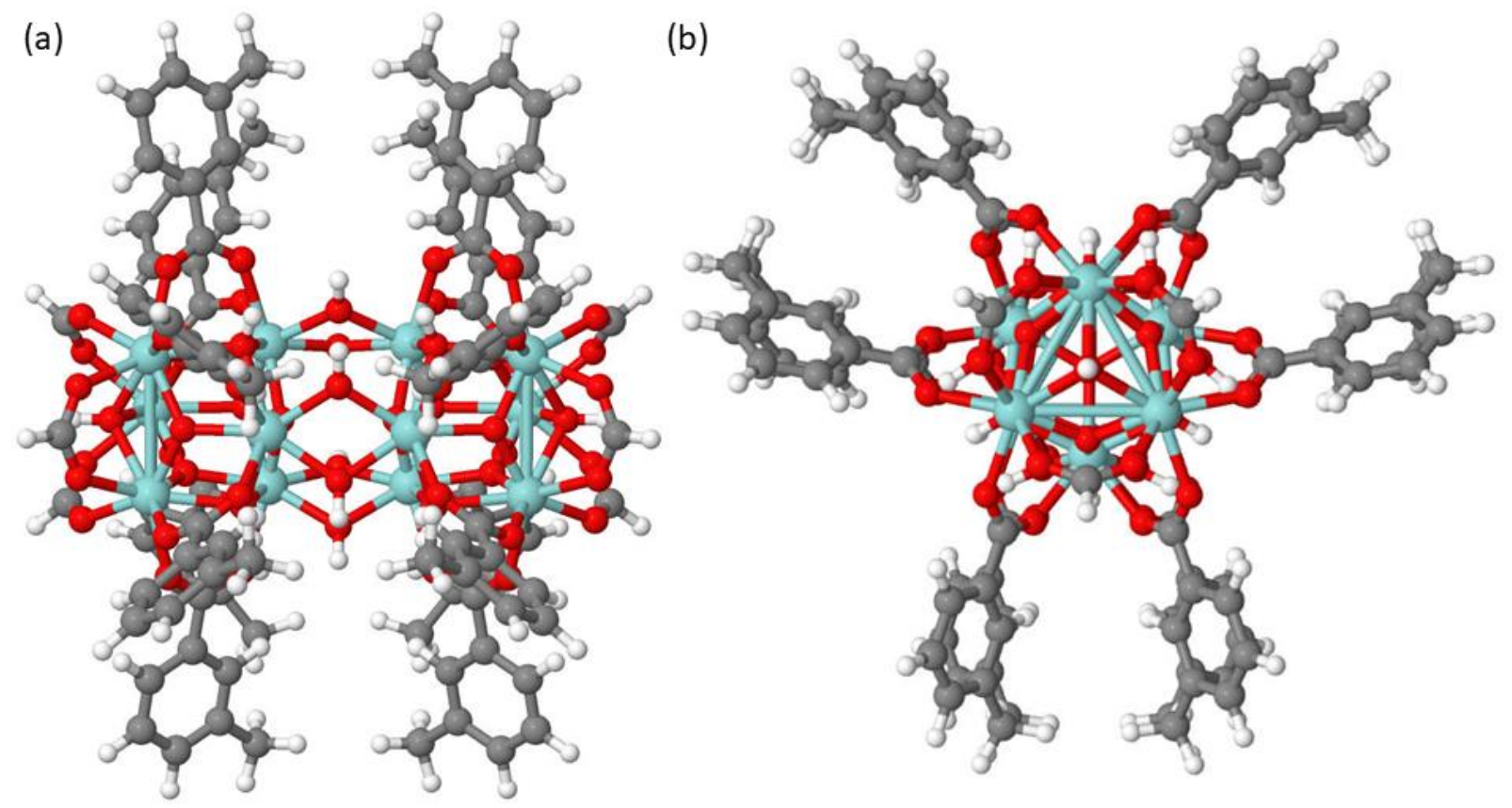

Figure $1 \quad(a, b)$ Structure of the Zr12 oxo-cluster (I) with the composition $\left[\mathrm{Zr}_{12}\left(\mu_{3}-\mathrm{O}\right)_{8}\left(\mu_{3}-\mathrm{OH}\right)_{8}\left(\mu_{2^{-}}\right.\right.$ $\mathrm{OH})_{6}(\mathrm{HCOO})_{6}(\mathrm{~L}-\mathrm{COO})_{12}$ ] $(\mathrm{L}-\mathrm{COO})_{8}$ ] (where $\mathrm{L}$ stands for a $4 \mathrm{~m}$-methylbenzene ring) comprising two subunits bridged by 6 protonated $\mu_{2}-\mathrm{O}$ site units, viewed down the $z$ - and $x$-axes, respectively. The $Z r, C$, $\mathrm{O}, \mathrm{H}$ atoms are represented by blue-gray, grey, red and white spheres, respectively. 


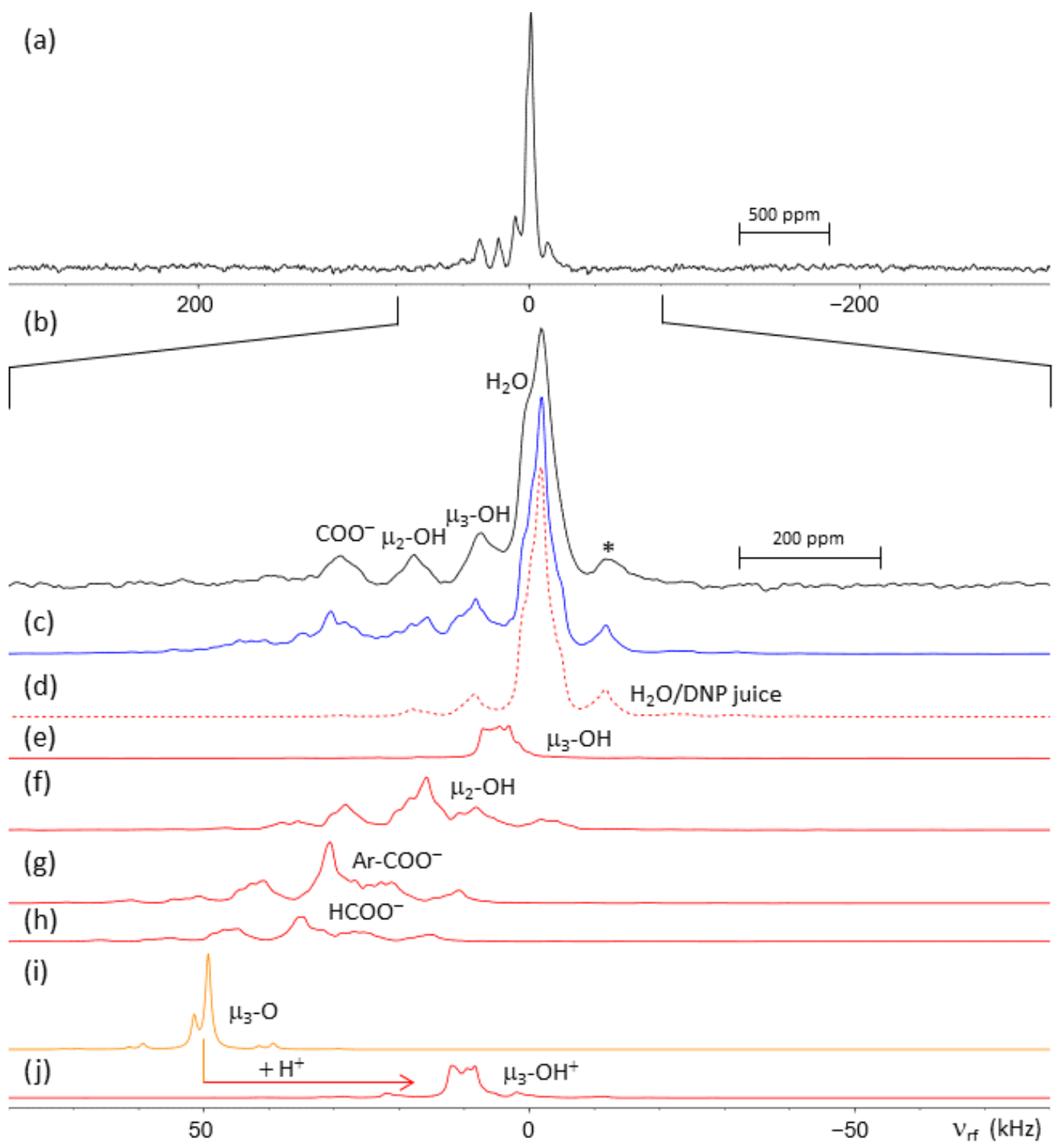

Figure 2 (a) Experimental DNP-enhanced ${ }^{1} \mathrm{H} \rightarrow{ }^{17} \mathrm{O} \mathrm{CP}$ MAS spectrum of a sample of ca. $30 \mathrm{mg}$ of MIP-206, a porous polycrystalline MOF containing Zr12 oxo-clusters (I) of the type shown in Fig. 1, with incipient wetness impregnation with an aqueous $\left(\mathrm{D}_{2} \mathrm{O}: \mathrm{H}_{2} \mathrm{O}=90: 10\right)$ solution without cryoprotectant containing $13 \mathrm{mM}$ of the biradical AMUPOL as polarizing agent, observed at $100 \mathrm{~K}$ in a $3.2 \mathrm{~mm}$ sapphire rotor spinning about the magic angle at $10 \mathrm{kHz}$ in a field $B_{0}=18.6 \mathrm{~T}\left(800 \mathrm{MHz}\right.$ for ${ }^{1} \mathrm{H}, 108.5 \mathrm{MHz}$ for $\left.{ }^{17} \mathrm{O}\right)$. The polarization of the protons was enhanced by dynamic nuclear polarization $\left(\varepsilon\left({ }^{1} \mathrm{H}\right)=\mathrm{S}_{\text {with }} / \mathrm{S}_{\text {without }}=28\right)$, using ca. $5 \mathrm{~W}$ of microwave irradiation at $527 \mathrm{GHz}$, prior to transfer to ${ }^{17} \mathrm{O}$ by cross-polarization. The assignments show 4 distinct ${ }^{17} \mathrm{O}$ sites. The asterisk indicates a spinning sideband. (c) Simulated ${ }^{17} \mathrm{O}$ spectrum obtained by summation of 6 spectra (d-h) shown in red. (d) Simulated signal of $\mathrm{H}_{2} \mathrm{O}$ from "DNP juice" used for incipient wetness impregnation of the porous solid. (e-i) Simulated ${ }^{17} \mathrm{O}$ subspectra of 5 distinct ${ }^{17} \mathrm{O}$ sites, based on NMR parameters calculated by DFT methods on structure (I) shown in Fig. 1. (i) Subspectrum for the missing unprotonated $\mu_{3}-\mathrm{O}$ sites (orange). (j) Subspectrum expected for a protonated $\mu_{3}-\mathrm{O}$ site (red). The relative intensities of subspectra (e-j) are proportional to their occurrence in structure (I), except for subspectrum (f) that was expanded vertically by a factor 4 . A line broadening of $1 \mathrm{kHz}$ was applied to all experimental and simulated spectra. 
(a)

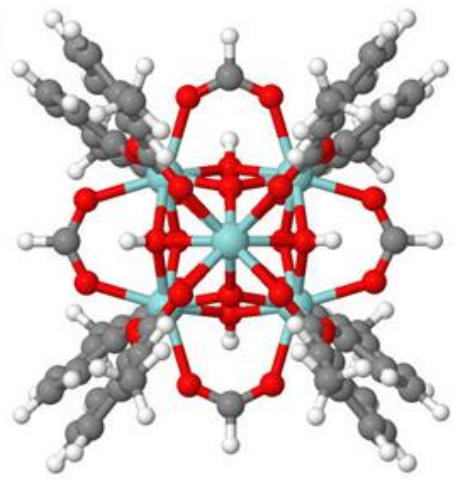

(b)

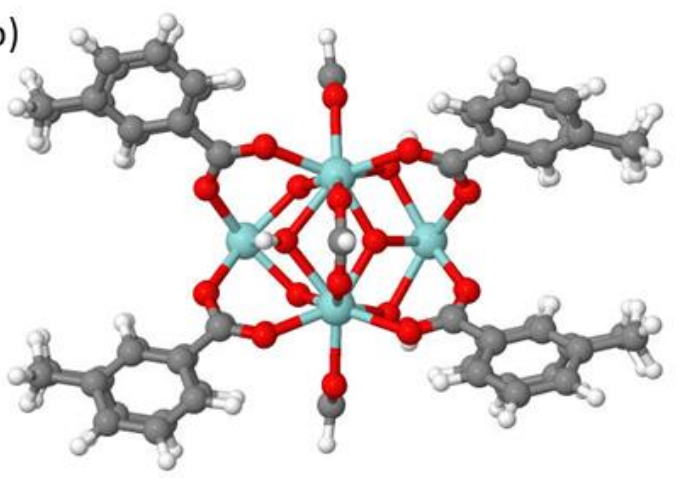

(c)

$$
\mu_{3}-\mathrm{O}
$$

$\mathrm{HCOO}^{-} \mathrm{Ar}_{-} \mathrm{COO}^{-}$

$$
\mu_{2}-\mathrm{OH}
$$

$\mu_{3}-\mathrm{OH}$

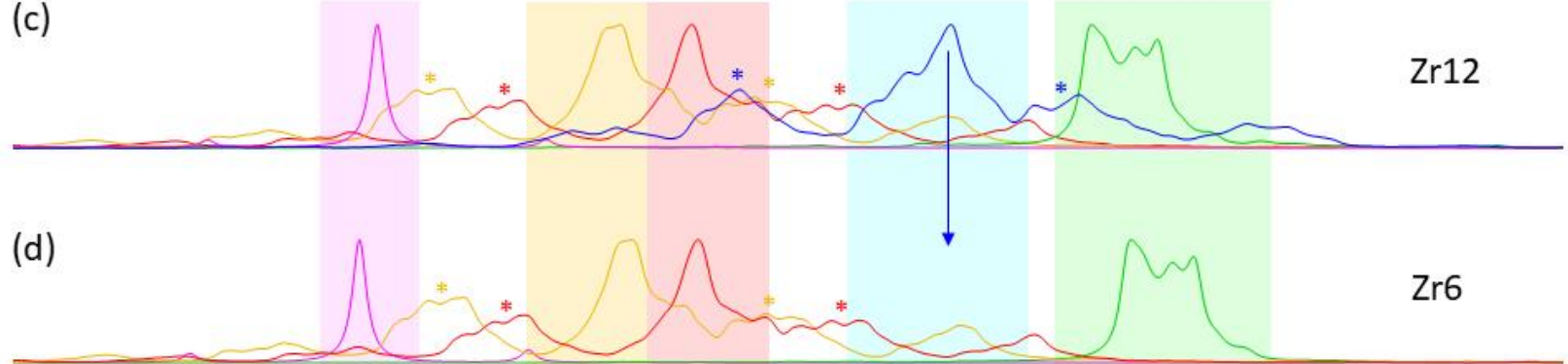

(e)

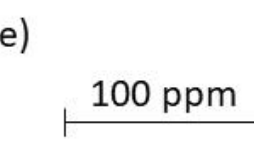

60

40

20

$$
v_{\text {rf }}(\mathrm{kHz})
$$

Figure $3 \quad(a, b)$ Views of Zr6-oxo-cluster (II) formulated $\left[\mathrm{Zr}_{6}\left(\mu_{3}-\mathrm{O}\right)_{4}\left(\mu_{3}-\mathrm{OH}\right)_{4}(\mathrm{HCOO})_{4}(\mathrm{~L}-\mathrm{COO})_{8}\right]$ (where $\mathrm{L}$ stands for a $4 \mathrm{~m}$-methylbenzene ring) showing that the core is similar to half of the Zr12 cluster (I), but without the $\left(\mu_{2}-\mathrm{OH}\right)_{3}$ bridges, viewed down the $z$ - and $x$-axes, respectively. (c) Superposition of simulated ${ }^{17} \mathrm{O}$ MAS spectra for the $6^{17} \mathrm{O}$ sites of the Zr12 oxo-cluster (I) of Fig. 1 assuming NMR parameters calculated with DFT methods. Colored boxes highlight different ${ }^{17} \mathrm{O}$ sites. Spinning sidebands for sites with large CSAs are indicated by color-coded asterisks. (d) Spectra analogous to (c) for the Zr6 cluster (II). (e) Simulated signal of $\mathrm{H}_{2}{ }^{17} \mathrm{O}$ in DNP juice. The signal of the bridging $\mu_{2}-\mathrm{OH}$ sites that are present in Zr12 oxo-cluster (I) but absent in Zr6 oxo-cluster (II) is highlighted by a vertical blue arrow. All subspectra were normalized to have the same peak heights for clarity. 